\title{
Método para el estudio de los motivos polícromos
}

\section{Beatriz Prado Campos}

\begin{abstract}
Resumen: Este artículo expone y propone un método de estudio no invasivo para el análisis de los motivos polícromos de las indumentarias de las esculturas policromadas. El método no afecta a la integridad física de la obra, es accesible ya que no requiere de un material específico o costoso, y está al alcance de un amplio grupo de profesionales. A partir de la implementación sistemática de la ficha de motivos polícromos, se obtendrá la información necesaria para determinar conclusiones relacionadas con los motivos decorativos, su técnica de ejecución y los tejidos polícromos (fondos) sobre los que se asientan. Finalmente, se ha aplicado el método descrito sobre un conjunto de 135 esculturas procedentes de Antequera (Málaga), confirmando la viabilidad del método de trabajo expuesto.
\end{abstract}

Palabras clave: motivos polícromos, método de estudio, ficha de motivos polícromos, técnicas polícromas, indumentaria y escultura.

\section{Método para o estudo de motivos polícromos}

Resumo: Este artigo expõe e propõe um método de estudo não-invasivo para a análise dos motivos polícromos dos trajes em esculturas policromadas. O método não afecta a integridade física da obra, é acessível, uma vez que não requere equipamento específico ou dispendioso e está disponível a um vasto grupo de profissionais. A partir da implementação sistemática de uma ficha de motivos polícromos, obter-seá a informação necessária para chegar a conclusões relacionadas com essas decorações, a sua técnica de execução e com os tecidos polícromos (fundos) sobre os quais assentam. Por fim, foi aplicado o método descrito a um conjunto de 135 esculturas provenientes de Antequera (Málaga), confirmando a viabilidade do sistema de trabalho exposto.

Palavras-chave: motivos polícromos, método de estudo, ficha de motivos polícromos, técnicas polícromas, indumentária e escultura.

\section{Method for studying polychrome patterns}

\begin{abstract}
This article exposes and proposes a non-invasive method for the analysis of the polychrome patterns on painted sculpture costumes. This method does not affect the physical integrity of the artwork, it is accessible (as it does not require specific or expensive equipment) and it is available to a wide group of professionals. Through the systematic implementation of a record sheet on polychrome patterns, indispensable information will be obtained in order to reach conclusions about the polychrome motives, their techniques of execution and the backgrounds upon which they are applied on. Finally, the method described was experimented on a set of 135 sculptures from Antequera (Málaga), confirming the feasibility of the method of work outlined.
\end{abstract}

Keywords: polychrome patterns, method of work, polychrome patterns record sheet, polychrome techniques, costume and sculpture. 


\section{Introducción}

La escultura en madera policromada de forma individualizada, como dentro un contexto iconográfico-retablístico, supone una de las manifestaciones del arte español por excelencia (Echeverría 1992: 4). La policromía por sí misma, tiene la capacidad de dotar de realismo a la talla, acercándola al pueblo y haciendo comprensible y directo su mensaje contribuyendo con ello a la funcionalidad testimonial de la obra. Cabe pensar que bajo estas circunstancias, la policromía sea objeto de numerosos estudios y análisis, pero nada más lejos de la realidad, a pesar de los esfuerzos por parte de profesionales del área de conservación-restauración.

A menudo observamos cómo su conocimiento y estudio queda relegado a un segundo plano, primando el análisis volumétrico de la obra. Esta circunstancia se agrava por los múltiples aspectos que se deben tener en cuenta (Fernández Pardo 2005: 53) a la hora de abordarla (datación, autoría, repolicromías, anacronismo entre talla-policromía, entre otras). Todos ellos son objeto de distintas disciplinas (Bruquetas, Carrasón y Gómez Espinosa 2003: 25) -difícilmente aunables en una sola persona, haciendo que llevar a cabo un riguroso estudio resulte extremadamente complejo.

En este artículo se expone un método de trabajo y conocimiento de los motivos polícromos de la escultura en madera dorada y policromada relacionado con su contexto (indumentaria que reviste la obra). El estudio propuesto es una forma de aproximación no invasiva para el bien, su estudio, conocimiento, valoración técnica que posteriormente permite extraer conclusiones, tanto a nivel de detalle de las policromías de una obra, como de un conjunto de piezas que tengan un nexo común. Al mismo tiempo resulta accesible y útil a un amplio campo de profesionales de distintas disciplinas con conocimientos sobre técnicas polícromas.

La viabilidad del método de trabajo queda manifiesta después de haberse aplicado con éxito sobre un conjunto de 135 esculturas exentas en madera dorada y policromada procedente de Antequera (Málaga), con una cronología entre los siglos XV al XVIII. Si bien, predominan las policromías de influencia ornamental barroca frente a las góticas o renacentistas en este ámbito geográfico.

\section{Objetivo y originalidad del método}

El objetivo principal planteado consiste en establecer y mostrar una metodología de trabajo para el conocimiento, documentación y extracción de conclusiones sobre las decoraciones polícromas de la escultura en madera dorada y policromada de cualquier ámbito geográfico o cronología. Esta aportación va destinada a todos aquellos investigadores o profesionales interesados en la documentación exhaustiva de las indumentarias polícromas en la escultura.

Como planteamiento metodológico, e influenciado por el volumen de piezas propuestas y estudiadas, y las circunstancias que las acontecen, se ha planteado como requisito fundamental, establecer un método de estudio directo y no invasivo de la obra. Basado en su análisis visual y toma de datos fotográfica, sin necesidad de acudir a costosos métodos de caracterización y estudio de materiales (Gómez González et al. 2002: 227-236), difícilmente abordables cuando se trata de estudiar un amplio número de piezas, o bien, por la imposibilidad de obtener los permisos necesarios o la accesibilidad a la obra para la extracción de las muestras. Este permite documentar los motivos decorativos polícromos y su contexto desde cierta distancia, contribuyendo activamente en la democratización y divulgación del propio método. 
Si la metodología en sí misma no presenta la clave de la originalidad del trabajo, puesto que sigue los preceptos de cualquier investigación científica, su interés y novedad reside en el objeto enfocado -escultura exenta policromada- y el tratamiento que de él se lleva a cabo.

En otras palabras, la originalidad reside en plantear un desarrollo metodológico de estudio sistemático, enfocado en la escultura exenta en madera dorada y policromada, concretada en el análisis de los motivos decorativos y su contexto (relacionando la ornamentación con la vestimenta sobre la que se aplica y la iconografía del personaje representado), frente al estudio de las decoraciones de la pintura sobre tabla (Santos Gómez 2005; López Zamora 2007), especialmente si éstas pertenecen a un ámbito museístico. Se priorizan las indumentarias polícromas frente a las carnaciones, más frecuentemente desarrolladas (Gañán Medina 1999).

La clave de esta propuesta es la presentación de un método económico y sencillo, pensado para aquellas esculturas integradas en los discursos iconográfico-retablístico que decoran nuestros inmuebles religiosos, denostadas y olvidadas en gran medida por no pertenecer a una elite artística. Muchos de ellos están abocadas a la exclusión en ambiciosos estudios, por no existir los medios suficientes, o la bondad de incluirlas en planes específicos de conservación que derivan en restauraciones de retablos como medio de conocimiento de las especificidades de esta tipología de obras.

Para obtener una aplicación efectiva del método y unas conclusiones fiables, veraces y concluyentes, había que seguir una trayectoria sistemática que tratara la información de cada obra con la misma rigurosidad e iguales parámetros. Este aspecto se ha concretado en la elaboración una ficha de motivos polícromos. Ésta ha sido creada como un instrumento con capacidad para, a un solo golpe de vista, contener la máxima información acerca de los motivos polícromos de la indumentaria de una obra, y su contextualización en el conjunto polícromo. Dicha información se relaciona con la vestimenta que decora -túnica o manto y determina si constituye el motivo decorativo, o si por el contrario, es la decoración de fondo sobre la que se asienta-. Además de contextualizarla de forma sencilla, aporta información sobre los datos generales de la escultura.

La aplicación de esta metodología a un conjunto de esculturas de un mismo autor, época, escuela o ámbito geográfico, permite obtener conclusiones novedosas acerca de los motivos decorativos, técnicas de ejecución, efectos pictóricos y utillaje empleado en la creación artística de las indumentarias polícromas de las esculturas. En muchos casos, se establecen unos patrones de ejecución que pueden servir en un futuro para autentificar y aportar nuevas autorías, aportando luz a este campo de estudio hasta ahora poco desarrollado de forma sistemática.

\section{Antecedentes}

Desde hace relativamente poco tiempo, se han llevado a cabo estudios centrados en las policromías de las esculturas. Se han creado grupos de trabajo formado por profesionales del sector de la conservación-restauración, vinculados con instituciones de reconocido prestigio del sector patrimonial como: Instituto Andaluz de Patrimonio Histórico, The Getty Conservation Institute, Institut Royal du Patrimoine Artistique, Instituto de Patrimonio Histórico Español, Grupo de Conservación del International Council of Musseum, entre otros.

Los grupos de trabajo que han contribuido al conocimiento del tema con la publicación de sus conclusiones son: el Grupo ICOM-CC de Sculpture, Polychromy and Architectural Decoration, del International Council of Museums (Preprints), y el proyecto de investigación europeo para el estudio 
de la escultura policromada dentro del Proyecto de Investigación del Programa Raphael de la Unión Europea (Proyecto Policromía).

Destacan las aportaciones al tema por parte de autores españoles, que han sido pioneros en la materia, abordando el estudio de la policromía de la escultura en madera policromada o pintura sobre tabla desde la perspectiva histórica, material y/o técnica principalmente. Algunos de ellos son: Pedro Echevarría Goñi, Rosaura García Ramos, Emilio Ruiz de Arcaute Martínez, Ma José González López, Rocío Bruquetas Galán, Enriqueta González Martínez, Fernando R. Bartolomé García, Domingo Sánchez Mesa, Ainhoa Rodríguez López, Teresa Gómez Espinosa, Agnes Le Gac, Ana Carrasón López de Letona, Consuelo Dalmau Moliner, Eva López Zamora, Sonia Santos Gómez, entre otros.

En general, desde la óptica de historiadores del arte ha predominado un enfoque histórico, dándole mayor relevancia a aspectos puramente relacionados con su historia material, iconográfica y documental, como así lo atestiguan los numerosos ensayos existentes. Sin embargo, cuando la policromía es abordada por especialistas de las Bellas Artes en general, y en particular por Conservadores-Restauradores, el enfoque se dirige hacia aspectos relacionados con las técnicas de dorado y las capas de preparación específicamente, pasando someramente por el análisis en profundidad de las técnicas decorativas o los efectos pictóricos que ofrecen. Otros estudios, se centran en aspectos materiales, haciendo especial relevancia en los materiales presentes mediante su identificación y posterior caracterización por medio de análisis científicos, o tecnológicos desarrollando aspectos constructivos y determinando el proceso de ejecución. Cuando el objetivo se basa específicamente en la ornamentación, predominan los estudios de pintura sobre tabla en detrimento de la policromía de las esculturas.

Pero, si hay un momento oportuno e inmejorables condiciones para documentar y estudiar los motivos decorativos, y por ende, la policromía de una escultura, esa situación se plantea durante la restauración de un retablo. Ella trae consigo el acceso directo a la obra, permitiendo su manipulación y la observación de y observar detalles que a cierta distancia se pierden, la habitual caracterización de materiales constructivos y técnicas artísticas que normalmente se realizan. Todo ello contribuye a conocer muchos datos que de otra forma no serían tan certeros, o simplemente inapreciables. Por esto resulta indispensable conocer los casos publicados acerca de las intervenciones de restauración de retablos, como: Retablo Mayor de la Catedral de Sevilla, Retablo Mayor de la Catedral de Tudela, Retablo Mayor de la Iglesia Parroquial de Albolote (Granada), Retablo y sarga de San Eutropio de El Espinar, Retablo de Santa Bárbara de la Catedral de Málaga, Retablo de Santa Ana de Sevilla, Retablo de la Catedral Vieja de Salamanca, Metodología para la intervención del Retablo de la Capilla Real de Granada y de la Iglesia de San Luis de los Franceses de Sevilla, entre otros.

\section{Aplicación del método de trabajo}

El método de estudio aplicado a la escultura exenta en madera dorada y policromada debe ser planteado sobre un objetivo concreto, es decir, obras con un elemento en común. Por ejemplo: pertenecer a un mismo retablo o inmueble, ser atribuidas a un mismo autor o cronología, o bien, hallarse en un ámbito geográfico concreto, como es el caso expuesto.

Para cualquiera de estos planteamientos, el punto de partida se inicia con el denominado reconocimiento del terreno, concretándose en la determinación del volumen de obras que se 
incluirán, la accesibilidad de las mismas y la viabilidad del estudio. La próspera ciudad de Antequera cuenta en la actualidad con un total de 23 inmuebles religiosos en activo, contenedores de 135 esculturas exentas en madera dorada y policromada. Las obras incluidas en el estudio son aquellas que han podido inspeccionarse durante el proceso de trabajo de campo, quedando fuera de él aquellas a las que no ha sido posible el acceso.

El siguiente paso a seguir, es la solicitud de los permisos necesarios para llevar a cabo la documentación in situ de las obras. Este punto no reviste mayor dificultad, puesto que el método planteado no implica la manipulación directa de las obras, y por lo tanto predispone positivamente a cooperar a los custodios de dichos bienes muebles. Los inmuebles incluidos en la praxis son gestionados en su mayoría por órdenes o agrupaciones religiosas, dos de ellos en cambio, son gestionados directamente por la corporación municipal. A este respecto, cabe destacar que el consistorio de Antequera destaca por el interés que manifiesta en la conservación y restauración de los bienes muebles e inmuebles del municipio, contribuyendo activamente con un taller de restauración municipal.

Uno de los momentos claves para el desarrollo del estudio lo constituye la toma de documentación fotográfica in situ, de las obras en sí mismas, de sus detalles polícromos y del entorno (retablo e inmueble) que las rodea e integra. Las 135 esculturas antequeranas fueron documentadas realizando un barrido fotográfico de las mismas en su correspondiente ubicación, tomando en la medida de lo posible macrofotografías de los detalles relacionados con la ejecución de la policromía. In situ, también se anotan referencias en cuanto a la ubicación dentro del inmueble, situación en el retablo, dimensiones aproximadas, posibles repolicromías o distribución de repintes, estado de conservación, y cualquier otro dato significativo que pueda aportar luz al estudio posterior.

Tras obtener los documentos gráficos de cada obra, necesarios para su estudio y contextualización, se vuelcan a soporte informático. El criterio para su agrupación y clasificación se estableció partiendo de lo más general (inmuebles) a lo más particular (primero, retablos y finalmente por obras). Al contar con 23 inmuebles, 80 retablos y 135 esculturas, muchas de ellas con idéntica iconografía o nombre, se añadió a cada obra un código de referencia alfanumérico como medida identificativa.

\section{Trabajo de Campo}

Obras con un elemento en común.

$>$ Reconocimiento del terreno

> Solicitud de permisos

> Documentación fotográfica in situ

$>$ Volcado de datos a soporte informático

> Aplicación de código de referencia

\section{Trabajo de Investigación}

$>$ Implementación de las fichas de motivos polícromos

> Criterio seleccionado de orden de clasificación

$>$ Análisis de datos

$>$ Conclusiones 
Un aspecto fundamental para la identificación de las obras lo constituye llevar a cabo un estudio a nivel histórico-artístico, acudiendo a la documentación bibliográfica existente. Este punto es transversal a todo el desarrollo de la propuesta metodológica, puesto que cuanto más detalles se conocen de una obra, nuevos descubrimientos o reinterpretaciones de la información se incorporan a las hipótesis preestablecidas.

Hasta el momento, el desarrollo del proceso metodológico está centrado en la fase: trabajo de campo, centrado en la obtención, recopilación y clasificación de datos. A partir de este punto, se ahonda en el objeto de la cuestión: el estudio de los motivos polícromos y su contexto directo, la base o fondo sobre el que se asientan, y los aspectos técnicos desarrollados en su ejecución. Para ello, resulta fundamental contar con un instrumento de captación de datos como es la Ficha de Motivos Polícromos, diseñada especialmente, por y para esta tipología de obras, y centrada fundamentalmente en las decoraciones polícromas de estilo barroco, por ser éstas el objeto práctico de este método.

La viabilidad de la Ficha de Motivos Polícromos como instrumento de obtención de información estándar, ha sido demostrada al implementarla con los datos conseguidos de las 135 esculturas exentas propuestas.

La implementación de los descriptores propuestos en la fichas de motivos polícromos exige la clasificación, selección y tratamiento infográfico de las imágenes más representativas tomadas de la documentación fotográfica obtenida in situ de cada escultura. Ello exige estudiar pormenorizadamente toda la documentación existente de cada obra, y mediante la selección de los parámetros propuestos para la cumplimentación de cada epígrafe, se alcanza a caracterizar los rasgos generales y particulares tanto de los motivos decorativos polícromos como las decoraciones de los fondos sobre los que se asientan.

Finalmente, a pesar de la voluminosa cantidad de información y documentos fotográficos e infográficos generados durante todo el proceso de trabajo de campo e investigación, el volumen principal de estudio queda reducido a un total de 135 fichas, una por cada una de las esculturas. Es obvio decir que este volumen de información resulta mucho más cómodo y factible para la obtención de conclusiones veraces y sistemáticas, tanto a nivel particular como general, acerca de las características polícromas de las indumentarias que visten las esculturas de este ámbito geográfico y cronológico, o de cualquier otro al que se aplique.

Al avanzar en la búsqueda de conclusiones y ahondando en los datos obtenidos, se hace necesario establecer un orden de clasificación de las 135 fichas. El criterio seleccionado de orden de clasificación, sin lugar a dudas debe estar relacionado directamente con el tema objeto de estudio: los motivos polícromos y sus técnicas de ejecución.

Tras varios ensayos de orden de clasificación, se puso de manifiesto que el verdadero nexo de unión estilístico entre una obra u otra, viene determinado por las técnicas de ejecución que hayan sido empleadas en la creación de sus motivos decorativos. Frente a este aspecto, presentan menor semejanza estilística aquellas obras realizadas con una misma gama cromática, técnica de ejecución para la decoración de los fondos, o la propia naturaleza (refiriéndose a la capacidad de pertenecer a una especie u otra) del motivo decorativo. Así por ejemplo, si varias indumentarias están decoradas con motivos florales, o un mismo color de fondo para el tejido policromado, no asegura su analogía estilística. Mientras que si los motivos decorativos son ejecutados con 
idénticas técnicas, independientemente de lo que representen, ofrecerán una mayor afinidad estilística.
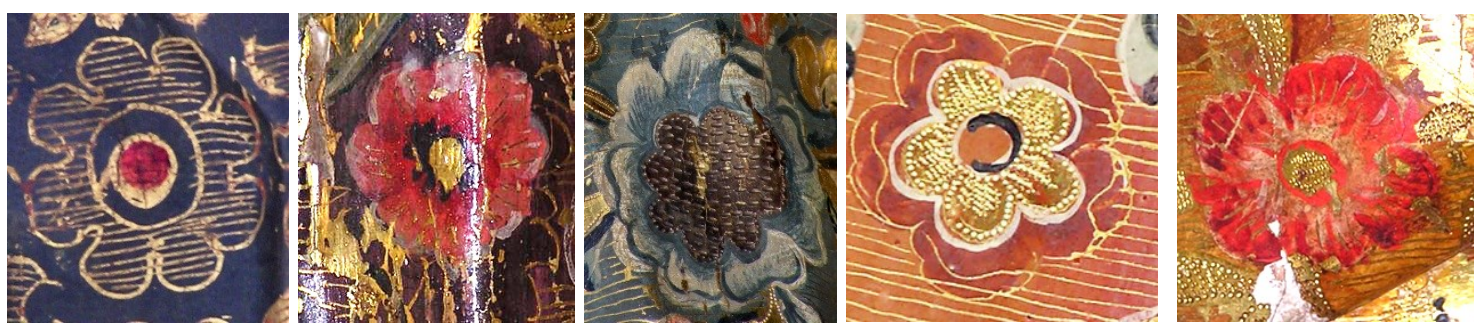

Todos estos motivos florales presentan una morfología muy similar; las semejanzas y diferencias entre ellos vienen determinadas por las técnicas y recursos plásticos utilizados en la ejecución de los mismos.

Finalmente, y en gran medida gracias al orden planteado y descrito para las fichas obtenidas, se pueden extraer todo tipo de conclusiones relacionándolas con cualquiera de los descriptores implementados, siendo este, el último eslabón de la cadena de investigación, de las policromías de un determinado ámbito.

\section{Ficha de Motivos Polícromos}

Como se ha manifestado anteriormente en la descripción de la aplicación del método, una de las claves del éxito en la extracción de conclusiones acerca de las características polícromas de la escultura antequerana está fundamentada en la utilización de la Ficha de Motivos Polícromos.

El diseño de la Ficha de Motivos Polícromos es determinante para el buen desarrollo del método, debía cumplir una serie de exigencias que facilitaran tras su implementación, la extracción de conclusiones veraces y contrastadas acerca del tema de estudio. Las exigencias requeridas y cumplidas han sido las siguientes:

- Incluir todos los datos relevantes a nivel general y específico de la escultura, y sus motivos polícromos en un solo documento, permitiendo en un golpe de vista toda la información.

- Mostrar las similitudes o divergencias técnicas y/o plásticas entre las distintas vestimentas que atavían a los distintos personajes iconográficos representados.

- Información concisa, amplia y exhaustiva acerca de la naturaleza, distribución, traspaso del dibujo y técnicas de ejecución de los motivos polícromos y su contexto más directo (fondo o tejido sobre el que se asientan los motivos decorativos y sus características formales).

- Uniformidad de contenidos y su tratamiento, para ello se establecen unos descriptores de estudio constantes a implementar.

- Crear una plantilla estándar (Ficha de Motivos Polícromos) que mantuviera el mismo formato sin variaciones dimensionales al implementar la información específica de cada escultura. Para ello se optó por trabajar con un software tipo Corel Draw 12. 


\section{Descripción formal de la Ficha de Motivos Polícromos}

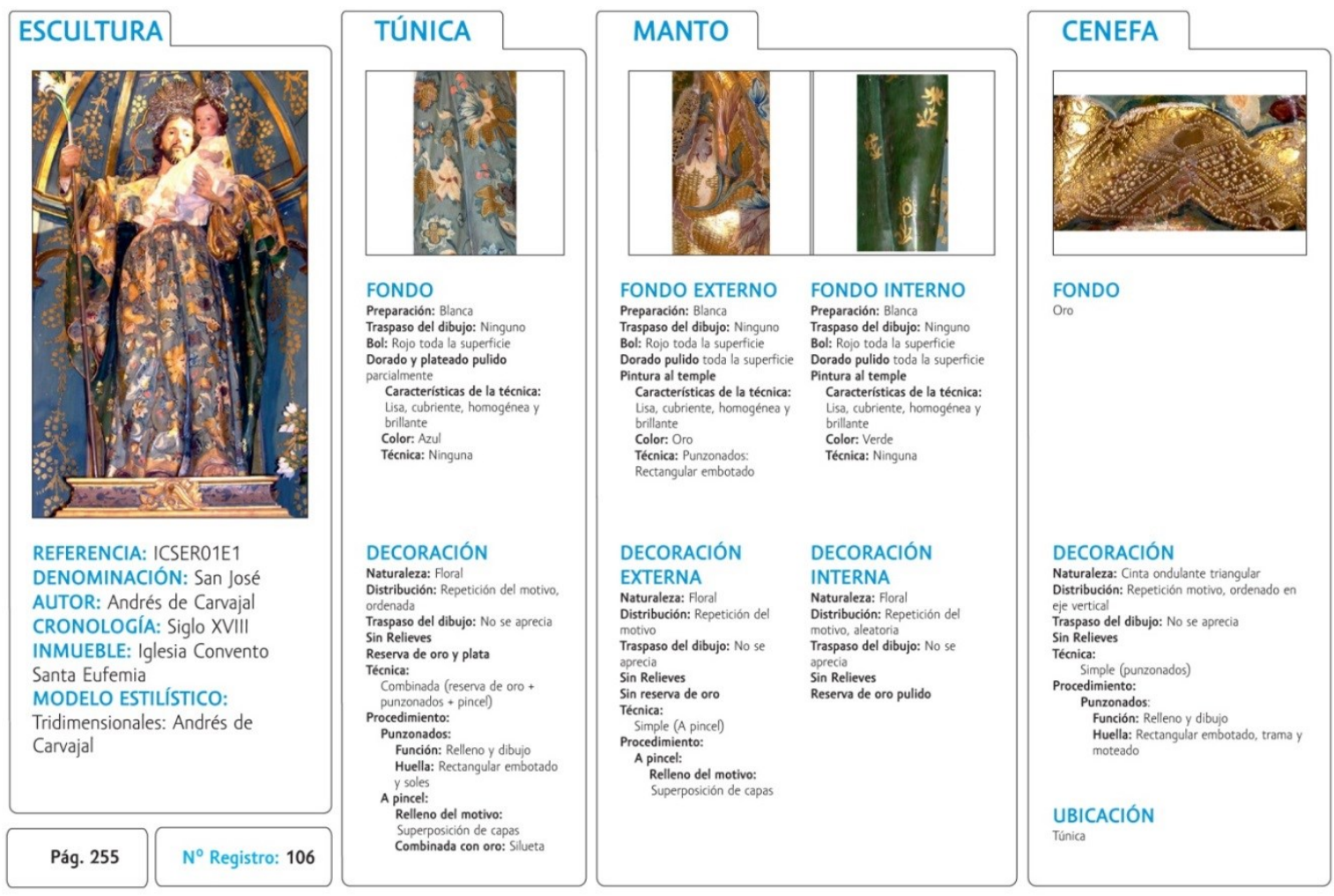

Ficha de Motivos Polícromos

La Ficha de Motivos Polícromos se presenta con una estructura homogénea y uniforme en formato apaisado. Dispuesta en cuatro columnas verticales remarcadas a modo de clasificadores con cajetín, en donde se inserta el título del tema principal (escultura, túnica, manto y cenefa).

En cada una de las columnas el espacio se divide en dos áreas fundamentales de lectura de información; fotografía acorde al tema de alusión y descriptores estándar de información. Dichos descriptores son uniformes y constantes en la Ficha de Motivos Polícromos, si ellos fueran modificados de una escultura a otra no existiría la posibilidad de estudiar y extraer conclusiones veraces sobre un grupo de policromías y sus motivos decorativos.

En la primera columna Escultura aparecen una serie de descriptores; "accesorios" para la documentación formal de la policromía, pero necesarios cuando se aplica este sistema metodológico de estudio sobre un conjunto de obras amplio y variado con el fin de extraer conclusiones sobre el mismo. Los parámetros referidos son los siguientes: referencia; clave que se asigna a cada escultura y la relaciona directamente con el inmueble y retablo en el que se ubica, Pág., establece un índice de páginas que se ordenan en función del $N^{\circ}$ de registro; este último es un número que se asigna en función del orden que se establece para clasificar las fichas obtenidas respecto a un conjunto de obras analizadas. El criterio de clasificación seleccionado y aplicado a las obras tomadas como muestra de la eficacia del método se basa en ordenarlas en función de la/s técnica/s que se emplean en la ejecución de los motivos que decoran la indumentaria de las esculturas. 
En las columnas túnica, manto y cenefa, se puede apreciar que la información se ha dividido en dos apartados claramente diferenciados: fondos y decoración. En el área Decoración se incluyen todos los datos relacionados con los motivos polícromos en sí mismos y las características de las técnicas de ejecución empleadas, mientras que en el área denominada Fondo, los motivos decorativos se contextualizan describiendo la base sobre la que se asientan.
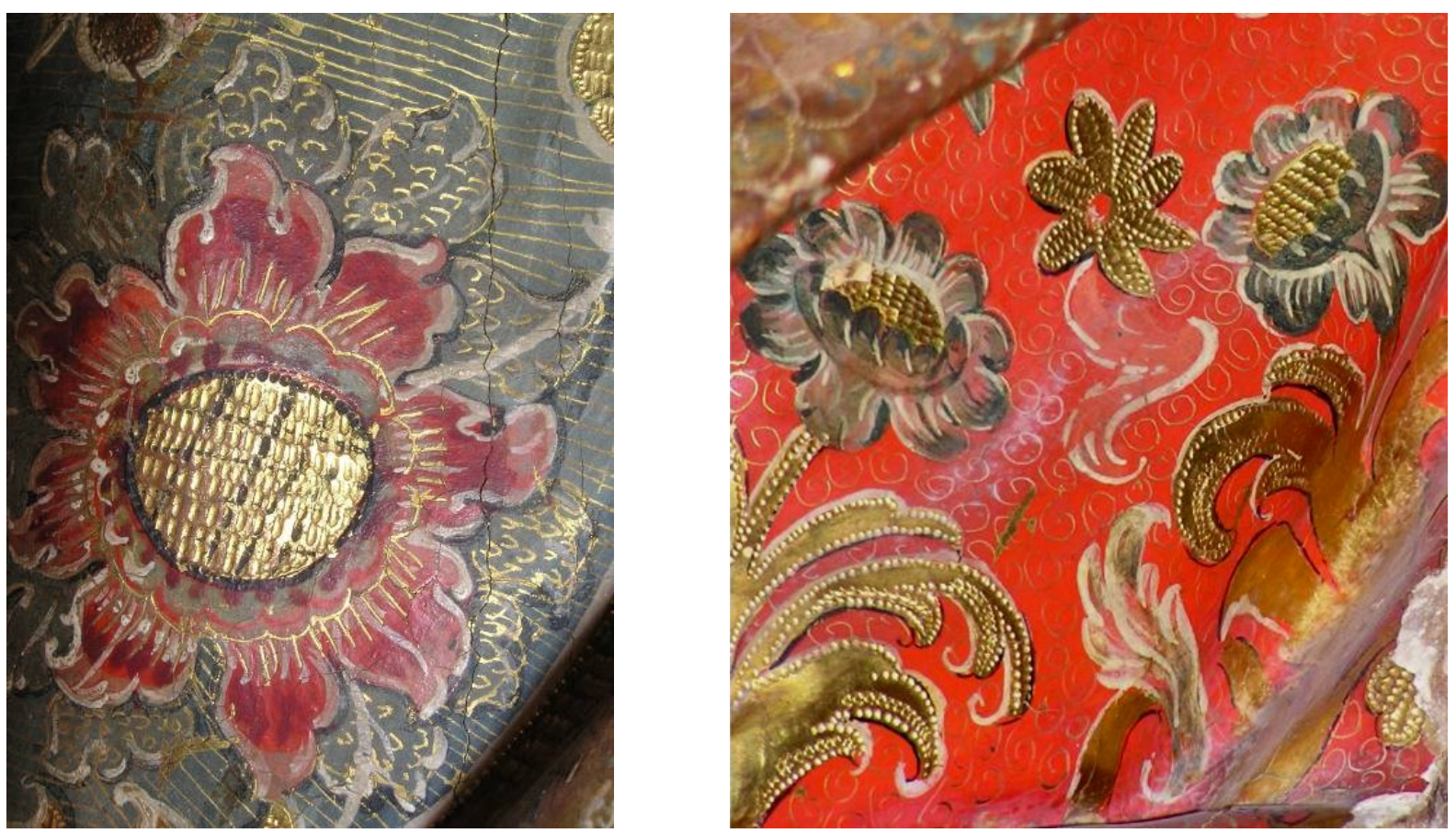

Los motivos decorativos o decoración de naturaleza floral se asientan sobre sendos fondos azul (izquierda) y rojo (derecha), esgrafiados con huellas en forma de rayados horizontales (izquierda) y roleos (derecha).

La columna manto incluye dos subapartados distribuidos verticalmente que tienen una correspondencia directa con la parte externa (anverso) y la parte interna (reverso) de los mantos o capas a los que hacen referencia. En la columna cenefa se incluye un tercer apartado en la zona inferior denominado ubicación para identificar claramente a que parte de la indumentaria pertenece, túnica y/o manto. Los datos propios de las cenefas se han planteado en una columna independiente y no como anexo inferior de las columnas túnica o manto, para propiciar la gestión del espacio, debido a la disposición arbitraria de las cenefas en las distintas vestimentas.

\section{Claves para el uso e implementación de datos en la Ficha de Motivos Polícromos}

Como anteriormente se ha especificado, los descriptores estándares de información son uniformes y constantes en todas las Ficha de Motivos Polícromos de cada una de las posibles esculturas a analizar. Sin embargo, los parámetros establecidos para su implementación, se han creado de acuerdo al conjunto de policromías analizadas como ejemplo de demostración del método no invasivo de estudio de motivos policromos6. En el presente estudio la autora se ha propuesto examinar los motivos polícromos de las indumentarias de la escultura exenta en madera dorada y policromada en Antequera (Málaga). Por ello, los posibles parámetros expuestos para cada uno de los descriptores incluidos en la ficha se adaptan a estas obras. 
Aunque la variedad de parámetros que se presenta es amplia, no hay que perder de vista que se han ajustado a las características polícromas de un área concreta. Y por tanto, no se debe considerar como un trabajo finalizado y cerrado, sino aceptarlo como una primera aproximación en la que se establecen las bases para futuras ampliaciones y nuevas aportaciones. Esto no haría más que constatar lo que ya es conocido, que la riqueza polícroma y técnica de la escultura policromada es amplísima y variada.

Los parámetros específicos de las técnicas artísticas se han nombrado atendiendo a la morfología o expresión artística que plantean, dejando al margen otro tipo de terminología basada en los conocimientos de contratos de obra u otros documentos históricos. Esta decisión viene en parte determinada ante la imposibilidad de contrastar esa terminología con documentación específica del área de Antequera. Por otro lado, se ha considerado más acertado emplear una terminología acorde a los efectos plásticos que persiguen estas técnicas o la forma que dejan impresa sobre la pintura.

A continuación, se ofrecen las claves para la implementación de cada uno de los descriptores estándar:

\section{Escultura}

- Referencia: código de registro o referencia asignado a cada obra.

- Denominación: título de la Escultura.

- Autor: creador del bien, en su defecto en aquellos casos en los que no se tenga constancia del artista, se pondrá el taller, escuela o círculo artístico al que pertenece si se conociera.

- Cronología: fecha de ejecución o contexto histórico.

- Inmueble: denominación del Inmueble en el que se encuentra.

- Modelo Estilístico': grupo estilístico al que pertenecen este tipo de policromías.

\section{Túnica, Manto (externo e interno) y Cenefa}

- Fondo²:

- Preparación: blanca o coloreada.

- Traspaso del dibujo: incisión en húmedo "U" o incisión en seco "V".

- Bol: rojo, anaranjado o amarillo. Parcial o en toda la superficie.

- Sin dorar, dorado pulido/bruñido, dorado mate o plateado pulido/bruñido.

- Características de la técnica: lisa o rugosa; cubriente o no cubriente; homogénea o desigual; brillante o mate.

- Color: blanco, amarillo, naranja, rosa, rojo, pardo claro, pardo oscuro, celeste, azul, violeta, morado, verde claro, verde oscuro, gris, negro, oro y plata (Tono de base uniforme).

\section{○ Técnica:}

- Punzonado3: rectangular embotado ${ }^{4}$, rectangular, cuadrado, trama, flor, ojeteado, moteado y soles. 
- Esgrafiados: rayado horizontal, oblicuo o vertical (discontinuo), ojeteado, escamado, moteado, moaré, zig-zag y roleos.

- Corladuras: sin motivos o con motivos

- Decoración ${ }^{5:}$

- Naturaleza $a^{6}$ floral, vegetal, línea recta, red cuadrada simple, red cuadrada compuesta, estrellas, armiño o concha. Mixta simple (floral + vegetal), (estrellas + epigrafía), (floral + red cuadrada) o (floral + guirnalda). Mixta compuesta (floral + vegetal + corazones), (floral + vegetal + red diagonal), (floral + vegetal + lazos) o (floral + vegetal + humana).

- Distribución: repetición del motivo, aleatorio u ordenado. Ordenado: en eje vertical u horizontal, en sentido vertical u horizontal y en cuadrícula.

○ Traspaso del dibujo: incisión en húmedo "U" o incisión en seco "V".

- Sin relieves o Con relieves.

- Sin dorar, dorado pulido, dorado mate o plateado pulido/bruñido.

- Técnica: simple (reserva de oro $^{7}$, punzonados, a pincel, esgrafiados o corlados) o combinada (reserva de oro + punzonados), (reserva de oro + pincel), (reserva de oro + esgrafiados), (dorado mate+ pincel), (reserva de oro + punzonados + pincel), (reserva de oro + punzonados + esgrafiados), (reserva de oro + punzonados + pincel+ esgrafiados), (reserva de oro + punzonados + pincel + corladuras).

○ Procedimiento:

- Punzonados:

- Función: relleno o dibujo (silueta o interior).

- Huella: rectangular embotado, rectangular, cuadrado, trama, flor, ojeteado, moteado y soles.

- A pincel:

- Relleno de color: tinta plana + silueta, tinta plana + luz/sombra, superposición de capas y degradación de color.

- Combinada con oro: Silueta o contorno del motivo, luz/sombra o sombra proyectada.

- Esgrafiados:

- Función: relleno o dibujo (silueta o interior).

- Huella: rayado horizontal, oblicuo o vertical (discontinuo), ojeteado, escamado, moteado, moaré, zig-zag, roleos, trazo fino o trazo grueso.

- Corladuras: sin motivos o con motivos.

El epígrafe Naturaleza del apartado Decoración cuando se refiere a las características de las Cenefas, presenta una diferencia sustancial respecto a sus homónimos túnicas y mantos, presentando una nomenclatura específica adaptada a los tipos de cenefas, como reflejo del análisis extraído de las obras estudiadas. Se especifican a continuación: 


\section{- Decoración (Cenefas)}

- Naturaleza: floral, cintas de follaje/zarcillo, flor de lis, cintas en zig-zag simples (flor), piedras preciosas, cintas lobuladas, sarta de perlas, cintas en zig-zag simples o triples (lis/palmeta), cintas en zig-zag polilobuladas (palmetas), cintas ondulantes triangulares (palmetas), cintas ondulantes con lazo, cintas ondulantes con elipses, cinta geométrica con rombos y círculos, o sin motivos.
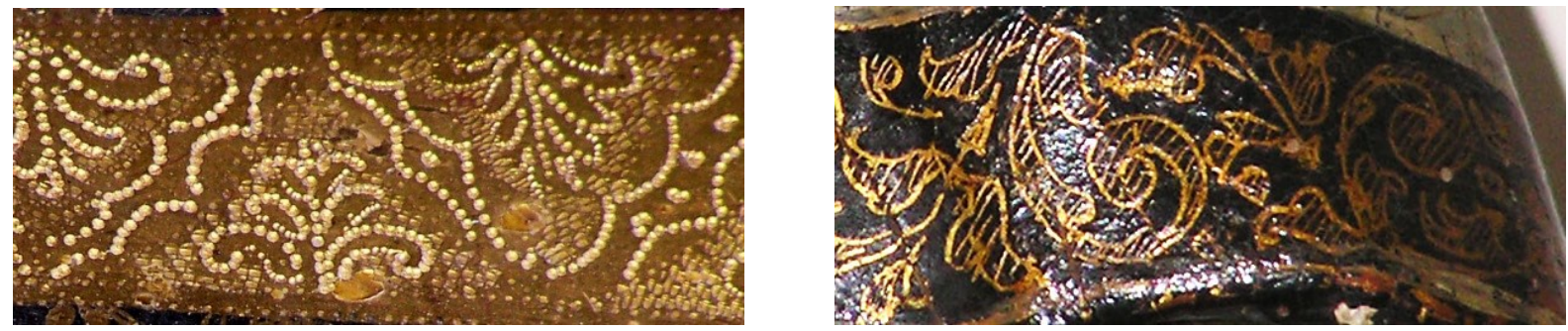

Detalle de las cenefas que rematan algunas indumentarias de las esculturas de Antequera.

\section{Resultados}

Como se ha apuntado anteriormente, todo el discurso procesual metodológico culmina con la obtención de las conclusiones, basadas fundamentalmente en los resultados (parámetros) obtenidos en cada uno de los descriptores de las fichas y su estudio comparativo.

Una de las primeras conclusiones obtenidas, extrapolable a otras piezas, es la semejanza que muestran aquellas policromías que utilizan las mismas técnicas artísticas en la ejecución de los motivos decorativos, independientemente de las empleadas para decorar los fondos sobre los que se asientan. Al agrupar y ordenar las obras antequeranas en relación con este aspecto, se han clasificado en torno a cinco grupos o modelos estilísticos, guardando todos ellos unas características comunes y relacionadas con las técnicas de ejecución empleadas en sus decoraciones polícromas.

Estos modelos estilísticos evolucionan desde policromías "monocromáticas" de aspecto plano, con indumentarias de color uniforme sin motivos decorativos, ciñéndose éstos a la ornamentación de las cenefas, entroncando así con la tradición más sobria del Concilio de Trento. Pasando a observar otras policromías, también de aspecto plano pero más sofisticado, denominadas "bidimensionales". En éstas, la técnica de ejecución empleada en las ornamentaciones tanto de los fondos como de los motivos decorativos son los esgrafiados, dificultando la diferencia entre el motivo y su fondo al quedar ambos en un mismo plano. Este tipo de policromías entronca con la tradición polícroma gótica como así lo atestigua la datación de las propias esculturas. Las más prolijas en Antequera, son aquellas policromías denominadas "tridimensionales". Se caracterizan por emplear todo tipo de técnicas y recursos plásticos en la ejecución de los motivos decorativos, en la incesante búsqueda de volumen, movimiento y en definitiva, realismo en la imitación de los tejidos históricos. En ellas, el motivo y el fondo se perciben en dos planos diferenciados en aras de la tridimensionalidad deseada. Las tres principales técnicas; punzonados, a pincel y esgrafiados, son utilizadas y combinadas en la creación de los motivos decorativos derivando en sofisticados y complejos diseños de naturaleza, generalmente floral y vegetal. 
Finalmente, configuran parte de estos cinco modelos estilísticos polícromos las obras atribuidas a los antequeranos Andrés de Carvajal (1709-1779) y la Familia de los Márquez; Diego Márquez y Vega (1724-1791) y su hijo Miguel Márquez García (1767-1826). En cada uno de ellos, entre sus obras se aprecian similitudes estilísticas relacionadas con los diseños, ejecución y distribución de los motivos decorativos. La gama cromática empleada, así como la combinación de las técnicas y recursos plásticos hacen que sus obras les caractericen y tengan nombre propio a pesar de formar parte del estilo polícromo barroco antequerano. Las pautas que se han establecido en el estudio de sus policromías, confiamos contribuyan en el futuro a identificar nuevas adjudicaciones.

Todo ello, favorece poner de manifiesto la existencia de un foco artístico antequerano, que gozó de reconocimiento en su momento histórico. Si bien, no logra alcanzar la consideración de escuela, como los focos artísticos de Granada o Sevilla, sí supone, un reconocimiento de una identidad propia en la que destacan las figuras de Andrés de Carvajal y la familia de los Márquez.

Técnicamente, la policromía de la escultura antequerana sigue la estratificación en capas tradicional, compuesta por: aparejo, bol, lámina de oro pulida, capa de color de fondo (azul, blanco o rojo son los más utilizados), decorados a base de esgrafiados con huellas de rayados horizontales (rajados). Las corladuras, como se viene apuntando en otros estudios (Echeverría 2002: 170), se relega a los interiores de los mantos y envés de las mangas.

Los motivos decorativos son utilizados para ornamentar las indumentarias, siendo de forma generalizada de naturaleza floral y vegetal, en donde abundan los rameados como elementos secundarios distribuidores de la composición. Para crearlos, los artistas recurren fundamentalmente a la utilización de punzonados combinados con retoques a pincel y reservas de oro o plata.

Uno de los aspectos más significativos y originales de este estudio, lo representa el hecho de haber elevado a las cenefas de las túnicas y mantos a la misma categoría de estudio que éstos. Mediante el análisis de las mismas, se ha determinado que no son intrínsecas a las túnicas o mantos, si no que se emplean en cierto modo, arbitrariamente. Se ha profundizado en el análisis de la naturaleza o diseño de los motivos decorativos que representan, llegando a clasificarlos según los parámetros señalados en el apartado decoración referido a cenefas, en la fichas de motivos polícromos. Los motivos predominantes en las decoraciones de las cenefas son las cintas de follaje o zarcillo, siguiéndoles las cintas en zig-zag simples y triples.

En definitiva, este método contribuye al estudio y análisis de las policromías y motivos decorativos de las indumentarias de las esculturas, incluyendo las cenefas que rematan las túnicas y mantos. Contextualizando y estableciendo relaciones entre los distintos elementos que componen y crean una policromía, yendo un paso más allá, al permitir establecer unas directrices acerca de un área de estudio con algún parámetro común.

\section{Notas}

[1] Este apartado se aclarará en las conclusiones del artículo. Se han establecido cinco grupos: monocromáticas, bidimensionales, tridimensionales, Andrés de Carvajal y Familia de los Márquez

[2] Los fondos constituyen una capa de color decorada o no, sobre la que resaltan los adornos, dibujos o motivos decorativos, situándose en un segundo plano.

[3] Método mecánico que imprime la huella del punzón mediante presión o percusión sobre una superficie polícroma, generalmente metálica pulida. 
[4] La huella impresa presenta forma rectangular con las esquinas ligeramente curvas.

[5] Se ha elegido el término decoración como sinónimo de motivo decorativo por ser más genérico y global, ya que las policromías en muchas ocasiones incluyen más de un tipo de motivo.

[6] La naturaleza de la decoración es entendida como la cualidad de pertenecer a una especie, genero o clase.

[6] Sólo parte de la superficie dorada o plateada pulida resulta visible, constituyendo el motivo decorativo en sí mismo o parte de él.

\section{Bibliografía:}

BARTOLOMÉ GARCÍA, F. (1997). "Pintura y policromía de los siglos XVII y XVIII en Orduña. El maestro pintor Juan Antonio de Jáuregui", Revista Ondare, 16: 143-166.

BRUQUETAS, R., CARRASÓN, A. y GÓMEZ ESPINOSA, T. (2003). "Los Retablos. Conocer y Conservar", Bienes Culturales, 2: 13-42.

BRUQUETAS GALÁN, R. (2004). "Los tableros de pincel. Técnicas y materiales", 2a ed. Madrid: Grupo Español de IIC.

CARRASÓN LÓPEZ DE LETONA, A., et al. (2002). "Las técnicas de dorado en los siglos XVII y XVIII en España." En Congresso Internacional Policromía. A escultura policromada religiosa dos séculos XVII e XVIII: Estudo comparativo das técnicas, alterações e conservação em Portugal, Espanha e Bélgica. Lisboa: Instituto Português de Conservação e restauro, 189-196.

DE LA FUENTE RODRÍGUEZ, L. A. (1998). “Corladura o 'meccha'. Evolución técnico-histórica”. Kermes, 31:42-56.

ECHEVARRIA GOÑI, P. L. (1990). La policromía del renacimiento en Navarra. Pamplona: Gobierno de Navarra.

ECHEVARRIA GOÑI, P. L. (1992). "Policromía renacentista y barroca." Cuadernos de Arte Español, 48: 31.

ECHEVARRIA GOÑI, P. L. (2002). "Evolución de la policromía en los siglos del Barroco. Fases ocultas, revestimientos, labores y motivos." En Congresso Internacional Policromía. A escultura policromada religiosa dos séculos XVII e XVIII: Estudo comparativo das técnicas, alterações e conservação em Portugal, Espanha e Bélgica. Lisboa: Instituto Português de Conservação e Restauro, 167-176.

FERNANDEZ PARDO, F. et al. (2005). La escultura en la ruta Jacobea: Arnao de Bruselas. Retablo Mayor de la Imperial Iglesia de Palacio. Logroño: Diócesis de Calahorra y la Calzada-Logroño.

GAÑÁN MEDINA, C. (1999). Técnicas y Evolución de la Imaginería Polícroma Sevillana. Sevilla: Universidad de Sevilla.

GARCÍA RAMOS, R. y RUIZ DE ARCAUTE, E. (1996). "Aproximación al brocado aplicado en España. Desarrollo y extensión." En XI Congreso de Conservación y Restauración de Bienes Culturales, Castellón: Grupo Español del IIC y Diputació de Castelló, 747-756.

GARCÍA RAMOS, R. y RUIZ DE ARCAUTE, E. (1997). "Aportaciones al estudio de correspondencias de policromías. Criterios y técnicas." Revista Kermes, 29: 7-12.

GÓMEZ ESPINOSA, T. (2004). "La policromía de los retablos. Estilos y Evolución”. 2ª ed. Madrid: Grupo Español de IIC.

GÓMEZ GONZÁLEZ, M., et al. (2002). "Estudio Analítico de la Policromía Castellana del Siglo XVII". En Congresso Internacional Policromía. A escultura policromada religiosa dos séculos XVII e XVIII: Estudo comparativo das técnicas, alterações e conservação em Portugal, Espanha e Bélgica. Lisboa: Instituto Português de Conservação e Restauro, 227-236. 
GONZÁLEZ LÓPEZ, M. J. (2004). “Una propuesta de ficha para la creación de una base de datos de retablos en madera policromada." En Séptimo Congreso Internacional de Rehabilitación del Patrimonio Arquitectónico y Edificación. Lanzarote: Centro Internacional para la Conservación del Patrimonio, 78-83.

LOPEZ ZAMORA, E. (2007). Estudio de los materiales y procedimientos del dorado a través de las fuentes literarias antiguas: Aplicación en las decoraciones de pinturas castellanas sobre tabla, Tesis Doctoral, Madrid: Universidad Complutense de Madrid.

LÓPEZ ZAMORA, E. y DALMAU MOLINER, C. (2006). "Estudio y clasificación de los motivos grabados en las superficies doradas de pinturas sobre madera. Propuesta de ficha de recogida de datos." En XV Congreso de Conservación y Restauración de Bienes Culturales. Murcia: Consejería de Educación y Cultura, Dirección General de Cultura, 191-202.

PRADO CAMPOS, B. (2005). Puesta a punto de una metodología de conocimiento y estudio de los motivos decorativos de la escultura exenta en madera policromada de los siglos XV al XVIII en cuatro iglesias de Antequera, Málaga: clasificación, estudio y técnica de ejecución. Inédito.

PRADO CAMPOS, B. (2011). Estudio comparativo de la policromía aplicada a la escultura exenta en madera de los siglos XV al XVIII en Antequera, Málaga: motivos ornamentales y técnicas de ejecución. Tesis Doctorla. Sevilla: Universidad de Sevilla.

SANTOS GÓMEZ, S. (2005). Las preparaciones de yeso en la pintura sobre tabla de la escuela española. Tesis Doctoral. Madrid: Universidad Complutense de Madrid.

SERUYA, A. I. (dir.) (2002). Actas do Congresso Internacional Policromía. A escultura policromada religiosa dos séculos XVII e XVIII: Estudo comparativo das técnicas, alterações e conservação em Portugal, Espanha e Bélgica: Lisboa, 29, 30 e 31 de outubro de 2002. Lisboa: Instituto Português de Conservação e Restauro.

SANCHEZ-MESA MARTÍN, D. (1971). Técnica de la escultura policromada granadina. Granada: Universidad de Granada.

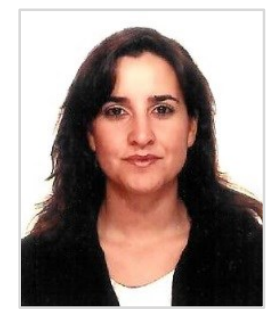

\section{Dra. Beatriz Prado Campos}

beatrizpradocampos@gmail.com

Doctora en Bellas Artes por la Universidad de Sevilla (2011). Conservadora-Restauradora licenciada en la Universidad de Granada. Su tesis doctoral se tituló Estudio comparativo de la policromía aplicada a la escultura exenta en madera de los siglos XV al XVIII en Antequera, Málaga: motivos ornamentales y técnicas de ejecución. Pertenece desde 2011 al Proyecto I+D+I: “Excavación, Estudio Histórico y Conservación de la tumba 33 de la necrópolis de Qubbet El-Hawa (Asúan, Egipto)" HAR2009-08600/HIST de la Universidad de Jaén. Actualmente, es docente en la Universidad de Sevilla en el Grado en Conservación y Restauración, e imparte las asignaturas de "Técnica y Ornamento: la Policromía Barroca e Imaginería Ligera" en el Máster en Escultura Barroca Española: desde los siglos de oro a la sociedad de la información y las redes sociales, de la Universidad Internacional de Andalucía. Gran parte de su desarrollo profesional como conservadora-restauradora está vinculado al Instituto Andaluz de Patrimonio Histórico (Sevilla), colaborando en Proyectos como El Salvador y la Iglesia de Santa Ana (Retablo Mayor) en Sevilla, recientemente, el Proyecto de la Sala de los Reyes de la Alhambra de Granada y Conservación de la Iglesia del Santo Cristo de la Salud de Málaga, además de colaborar con otras instituciones, empresas privadas y proyectos particulares.

Artículo enviado el 31/01/2013

Artículo aceptado el 28/10/2013 